CUBO A Mathematical Journal Vol.13, № 01, (11-24). March 2011

\title{
Weak Convergence Theorems for Maximal Monotone Operators with Nonspreading mappings in a Hilbert space
}

\author{
Hiroko MAnAKA ${ }^{1}$ And WATARU TAKAhashi ${ }^{2}$ \\ Department of Mathematical and Computing Sciences, \\ Tokyo Institute of Technology, \\ Ohokayama, Meguroku, Tokyo 152-8552, Japan. \\ email: hiroko.Manaka@is.titech.ac.jp \\ email: wataru@is.titech.ac.jp
}

\begin{abstract}
Let $C$ be a closed convex subset of a real Hilbert space $H$. Let $T$ be a nonspreading mapping of $C$ into itself, let $A$ be an $\alpha$-inverse strongly monotone mapping of $C$ into $H$ and let $B$ be a maximal monotone operator on $H$ such that the domain of $B$ is included in $C$. We introduce an iterative sequence of finding a point of $F(T) \cap(A+B)^{-1} 0$, where $F(T)$ is the set of fixed points of $T$ and $(A+B)^{-1} 0$ is the set of zero points of $A+B$. Then, we obtain the main result which is related to the weak convergence of the sequence. Using this result, we get a weak convergence theorem for finding a common fixed point of a nonspreading mapping and a nonexpansive mapping in a Hilbert space. Further, we consider the problem for finding a common element of the set of solutions of an equilibrium problem and the set of fixed points of a nonspreading mapping.
\end{abstract}

\section{RESUMEN}

Sea $C$ un subconjunto convexo cerrado de un espacio real de Hilbert $H$. Sea $\mathrm{T}$ una asignación de $C$ en sí mismo, sea $A$ una asignación monótona $\alpha$-inversa de $C$ en $H$ y 
sea $B$ un operador monotono máximal en $H$ tal que el dominio de $B$ está incluido en $C$. Se introduce una secuencia iterativa para encontrar un punto de $F(T) \cap(A+B)^{-1} 0$, donde $F(T)$ es el conjunto de puntos fijos de $T$ y $(A+B)^{-1} 0$ es el conjunto de los puntos cero de $A+B$. Entonces, se obtiene el resultado principal que se relaciona con la convergencia débil de la secuencia.

Utilizando este resultado, obtenemos un teorema de convergencia para encontrar un punto común de una asignación fija y una asignación en un espacio de Hilbert. Además, consideramos el problema para encontrar un elemento común del conjunto de soluciones de un problema de equilibrio y el conjunto de puntos fijos de una asignación.

Keywords: Nonspreading mapping, maximal monotone operator, inverse strongly-monotone mapping, fixed point, iteration procedure.

Mathematics Subject Classification: 46C05.

\section{Introduction}

Let $H$ be a real Hilbert space with inner product $\langle\cdot, \cdot\rangle$ and induced norm $\|\cdot\|$ and let $C$ be a nonempty closed convex subset of $H$. For a constant $\alpha>0$, the mapping $A: C \rightarrow H$ is said to be $\alpha$-inverse strongly monotone if for any $x, y \in C$,

$$
\langle x-y, A x-A y\rangle \geq \alpha\|A x-A y\|^{2} .
$$

It is well-known that an $\alpha$-inverse strongly monotone mapping is also Lipschitz continuous with a Lipschitz constant $\frac{1}{\alpha}$. Let $S$ be a mapping of $C$ into itself. We denote by $F(S)$ the set of fixed points of $S$. A mapping $S$ of $C$ into itself is nonexpansive if

$$
\|S u-S v\| \leq\|u-v\|, \quad \forall u, v \in C
$$

If $S: C \rightarrow C$ is a nonexpansive mapping, then $I-S$ is $\frac{1}{2}$-inverse strongly monotone, where $I$ is the identity mapping on $H$; see, for instance, [18]. A mapping $S$ of $C$ into itself is nonspreading if

$$
2\|S u-S v\|^{2} \leq\|S u-v\|^{2}+\|S v-u\|^{2}, \quad \forall u, v \in C
$$

see [6, 7]. A multi-valued mapping $B \subset H \times H$ is said to be monotone if $\langle x-y, u-v\rangle \geq 0$ for all $x, y \in H, u \in B x$ and $v \in B y$. A monotone operator $B$ on $H$ is said to be maximal if its graph is not properly contained in the graph of any other monotone operator on $H$. Recently, in the case when $S: C \rightarrow C$ is a nonexpansive mapping, $A: C \rightarrow H$ is an $\alpha$-inverse strongly monotone mapping and $B \subset H \times H$ is a maximal monotone operator, Takahashi, Takahashi and Toyoda [15] proved a strong convergence theorem for finding a point of $F(S) \cap(A+B)^{-1} 0$, where $F(S)$ is the set of fixed points of $S$ and $(A+B)^{-1} 0$ is the set of zero points of $A+B$. 
In this paper, motivated by Takahashi, Takahashi and Toyoda [15], we introduce an iteration sequence of finding a common point of the set $F(S)$ of fixed points of a nonspreading mapping $S$ and the set $(A+B)^{-1} 0$ of zero points of $A+B$, where $A: C \rightarrow H$ is an $\alpha$-inverse strongly monotone mapping and $B \subset H \times H$ is a maximal monotone operator. Then, we prove a weak convergence theorem. Using this result, we get a weak convergence theorem for finding a common fixed point of a nonspreading mapping and a nonexpansive mapping in a Hilbert space. Further, we obtain a weak convergence theorem for finding a common element of the set of solutions of an equilibrium problem and the set of fixed points of a nonspreading mapping.

\section{Preliminaries}

Throughout this paper, let $\mathbb{N}$ be the set of positive integers and let $H$ be a real Hilbert space with inner product $\langle\cdot, \cdot\rangle$ and norm $\|\cdot\|$. A Hilbert space satisfies Opial's condition [10], that is,

$$
\liminf _{n \rightarrow \infty}\left\|x_{n}-u\right\|<\liminf _{n \rightarrow \infty}\left\|x_{n}-v\right\|
$$

if $x_{n} \rightarrow u$ and $u \neq v$; see [10]. Let $C$ be a nonempty closed convex subset of a Hilbert space $H$. The nearest point projection of $H$ onto $C$ is denoted by $P_{C}$, that is, $\left\|x-P_{C} x\right\| \leq\|x-y\|$ for all $x \in H$ and $y \in C$. Such $P_{C}$ is called the metric projection of $H$ onto $C$. We know that the metric projection $P_{C}$ is firmly nonexpansive, i.e.,

$$
\left\|P_{C} x-P_{C} y\right\|^{2} \leq\left\langle P_{C} x-P_{C} y, x-y\right\rangle
$$

for all $x, y \in H$. Further $\left\langle x-P_{C} x, y-P_{C} x\right\rangle \leq 0$ holds for all $x \in H$ and $y \in C$; see, for instance, $[16]$.

Let $\alpha>0$ be a given constant. A mapping $A: C \rightarrow H$ is said to be $\alpha$-inverse strongly monotone if $\langle x-y, A x-A y\rangle \geq \alpha\|A x-A y\|^{2}$ for all $x, y \in C$. We have that $\|A x-A y\| \leq(1 / \alpha)\|x-y\|$ for all $x, y \in C$ if $A$ is $\alpha$-inverse strongly monotone. Let $B$ be a mapping of $H$ into $2^{H}$. The effective domain of $B$ is denoted by $D(B)$, that is, $D(B)=\{x \in H: B x \neq \emptyset\}$. A multi-valued mapping $B$ is said to be a monotone operator on $H$ if $\langle x-y, u-v\rangle \geq 0$ for all $x, y \in D(B), u \in B x$, and $v \in B y$. A monotone operator $B$ on $H$ is said to be maximal if its graph is not properly contained in the graph of any other monotone operator on $H$. For a maximal monotone operator $B$ on $H$ and $r>0$, we may define a single-valued operator $J_{r}=(I+r B)^{-1}: H \rightarrow D(B)$, which is called the resolvent of $B$ for $r>0$. Let $B$ be a maximal monotone operator on $H$ and let $B^{-1} 0=\{x \in H: 0 \in B x\}$. It is known that the resolvent $J_{r}$ is firmly nonexpansive and $B^{-1} 0=F\left(J_{r}\right)$ for all $r>0$.

We give the crucial lemmas in order to prove the main theorem.

Lemma 2.1 ([12]). Let $H$ be a real Hilbert space, let $\left\{\alpha_{n}\right\}$ be a sequence of real numbers such that $0<a \leq \alpha_{n} \leq b<1$ for all $n \in \mathbb{N}$ and let $\left\{v_{n}\right\}$ and $\left\{w_{n}\right\}$ be sequences in $H$ such that for some $c$, $\lim \sup _{n \rightarrow \infty}\left\|v_{n}\right\| \leq c$, $\lim \sup _{n \rightarrow \infty}\left\|w_{n}\right\| \leq c$ and $\lim \sup _{n \rightarrow \infty}\left\|\alpha_{n} v_{n}+\left(1-\alpha_{n}\right) w_{n}\right\|=c$. Then $\lim _{n \rightarrow \infty}\left\|v_{n}-w_{n}\right\|=0$. 
Lemma 2.2 ([19]). Let $H$ be a Hilbert space and let $S$ be a nonempty closed convex subset of $H$. Let $\left\{x_{n}\right\}$ be a sequence in $H$. If $\left\|x_{n+1}-x\right\| \leq\left\|x_{n}-x\right\|$ for all $n \in \mathbb{N}$ and $x \in S$, then $\left\{P_{S}\left(x_{n}\right)\right\}$ converges strongly to some $z \in S$, where $P_{S}$ stands for the metric projection on $H$ onto $S$.

Using Opial's theorem [10], we can also prove the following lemma; see, for instance, [18].

Lemma 2.3. Let $H$ be a Hilbert space and let $\left\{x_{n}\right\}$ be a sequence in $H$ such that there exists a nonempty subset $S \subset H$ satisfying (i) and (ii):

(i) For every $x^{*} \in S, \lim _{n \rightarrow \infty}\left\|x_{n}-x^{*}\right\|$ exists:

(ii) if a subsequence $\left\{x_{n_{j}}\right\} \subset\left\{x_{n}\right\}$ converges weakly to $x^{*}$, then $x^{*} \in S$.

Then there exists $x_{0} \in S$ such that $x_{n} \rightarrow x_{0}$.

Let $C$ be a nonempty closed convex subset of a real Hilbert space $H$, let $f: C \times C \rightarrow \mathbb{R}$ be a bifunction and let $A: C \rightarrow H$ be a nonlinear mapping. Then, we consider the following equilibrium problem [8]: Find $z \in C$ such that

$$
f(z, y)+\langle A z, y-z\rangle \geq 0, \quad \forall y \in C
$$

The set of such $z \in C$ is denoted by $E P(f, A)$, i.e.,

$$
E P(f, A)=\{z \in C: f(z, y)+\langle A z, y-z\rangle \geq 0, \forall y \in C\}
$$

In the case of $A \equiv 0, E P(f, A)$ is denoted by $E P(f)$. In the case of $F \equiv 0, E P(f, A)$ is also denoted by $V I(C, A)$. For solving the equilibrium problem, let us assume that the bifunction $f$ satisfies the following conditions:

(A1) $f(x, x)=0$ for all $x \in C$;

(A2) $f$ is monotone, i.e., $f(x, y)+f(y, x) \leq 0$ for all $x, y \in C$;

(A3) for all $x, y, z \in C$, $\limsup f(t z+(1-t) x, y) \leq f(x, y)$;

(A4) $f(x, \cdot)$ is convex and lower semicontinuous for all $x \in C$.

We know the following lemmas; see, for instance, [1] and [2].

Lemma 2.4 ([1]). Let $C$ be a nonempty closed convex subset of $H$, let $f$ be a bifunction from $C \times C$ to $\mathbb{R}$ satisfying (A1)-(A4) and let $r>0$ and $x \in H$. Then, there exists $z \in C$ such that

$$
f(z, y)+\frac{1}{r}\langle y-z, z-x\rangle \geq 0
$$

for all $y \in C$. 
Lemma 2.5 ([2]). For $r>0$ and $x \in H$, define the resolvent $T_{r}: H \rightarrow C$ of $f$ for $r>0$ as follows:

$$
T_{r} x=\left\{z \in C: f(z, y)+\frac{1}{r}\langle y-z, z-x\rangle \geq 0, \forall y \in C\right\}
$$

for all $x \in H$. Then, the following hold:

(i) $T_{r}$ is single-valued;

(ii) $T_{r}$ is firmly nonexpansive, i.e., for all $x, y \in H$,

$$
\left\|T_{r} x-T_{r} y\right\|^{2} \leq\left\langle T_{r} x-T_{r} y, x-y\right\rangle ;
$$

(iii) $F\left(T_{r}\right)=E P(f)$;

(iv) $E P(f)$ is closed and convex.

\section{Main result}

Let $H$ be a real Hilbert space and let $C$ be a nonempty closed convex subset of $H$. Then, a mapping $S$ of $C$ into itself is nonspreading if

$$
2\|S u-S v\|^{2} \leq\|S u-v\|^{2}+\|S v-u\|^{2}, \quad \forall u, v \in C ;
$$

see $[6,7]$. We know from $[6,7,3]$ that if the bifunction $f: C \times C \rightarrow \mathbb{R}$ satisfies the conditions (A1), (A2), (A3) and (A4), then for any $r>0, T_{r}$ is a nonspreading mapping of $C$ into itself. Further, we can give the following example of nonspreading mappings in a Hilbert space. Let $H$ be a real Hilbert space; see [4]. Set $E=\{x \in H:\|x\| \leq 1\}, D=\{x \in H:\|x\| \leq 2\}$ and $C=\{x \in H:\|x\| \leq 3\}$. Define a mapping $S: C \rightarrow C$ as follows:

$$
S x \begin{cases}0, & x \in D, \\ P_{E} x, & x \notin D .\end{cases}
$$

Then, this mapping $S$ is not nonexpansive but nonspreading because it is not continuous. This implies that the class of nonexpansive mappings does not contain the class of nonspreading mappings. Now, we can prove a weak convergence theorem. Before proving it, we give the following lemma.

Lemma 3.1. Let $H$ be a real Hilbert space and let $C$ be a nonempty closed convex subset of $H$. Let $\alpha>0$. Let $A$ be an $\alpha$-inverse strongly monotone mapping of $C$ into $H$ and let $B$ be a maximal monotone operator on $H$ such that the domain of $B$ is included in $C$. Let $J_{\lambda}=(I+\lambda B)^{-1}$ be the resolvent of $B$ for any $\lambda>0$. Then, the following hold:

(i) If $u, v \in(A+B)^{-1} 0$, then $A u=A v$; 
(ii) for any $\lambda>0, u \in(A+B)^{-1}(0)$ if and only if $u=J_{\lambda}(I-\lambda A) u$.

Proof. (i) If $u, v \in(A+B)^{-1}(0)$, then $0 \in A u+B u$ and $0 \in A v+B v$. Then, we have $-A u \in B u$ and $-A v \in B v$. Since $B$ is monotone, we have $\langle u-v,-A u-(-A v)\rangle \geq 0$. On the other hand, since $A$ is $\alpha$-inverse strongly monotone, we have $\langle u-v, A u-A v\rangle \geq\|A u-A v\|^{2}$. So, we have $\langle u-v,-A u-(-A v)\rangle=0$ and hence $A u=A v$.

(ii) For any $\lambda>0$, we have that

$$
\begin{aligned}
& u=J_{\lambda}(I-\lambda A) u \\
& \Leftrightarrow u-\lambda A u \in u+\lambda B u \\
& \Leftrightarrow 0 \in \lambda A u+\lambda B u \\
& \Leftrightarrow 0 \in A u+B u \\
& \Leftrightarrow u \in(A+B)^{-1}(0) .
\end{aligned}
$$

This completes the proof.

Now, we can prove the main theorem.

Theorem 3.1. Let $C$ be a nonempty convex closed subset of a real Hilbert space $H$, let $A$ : $C \rightarrow H$ be $\alpha$-inverse strongly monotone, let $B: D(B) \subset C \rightarrow 2^{H}$ be maximal monotone, let $J_{\lambda}=(I+\lambda B)^{-1}$ be the resolvent of $B$ for any $\lambda>0$, and let $T: C \rightarrow C$ be a nonspreading mapping. Assume that $F(T) \cap(A+B)^{-1}(0) \neq \emptyset$. For any $x=x_{1} \in C$, define

$$
x_{n+1}=\beta_{n} x_{n}+\left(1-\beta_{n}\right) T\left(J_{\lambda_{n}}\left(I-\lambda_{n} A\right) x_{n}\right), \quad \forall n \in \mathbb{N},
$$

where $\left\{\beta_{n}\right\}$ and $\left\{\lambda_{n}\right\}$ satisfy the following conditions $(*)$ :

$$
0<c \leq \beta_{n} \leq d<1 \text { and } 0<a \leq \lambda_{n} \leq b<2 \alpha .
$$

Then, $x_{n} \rightarrow z_{0} \in F(T) \cap(A+B)^{-1}(0)$, where $z_{0}=\lim _{n \rightarrow \infty} P_{F(T) \cap(A+B)^{-1}(0)}\left(x_{n}\right)$.

Proof. Set $E=F(T) \cap(A+B)^{-1}(0)$. Let $y_{n}=J_{\lambda_{n}}\left(I-\lambda_{n} A\right) x_{n}$ for all $n \in \mathbb{N}$ and let $z \in E$. Since $z=J_{\lambda_{n}}\left(I-\lambda_{n} A\right) z$ from Lemma 3.1 and $A$ is $\alpha$-inverse strongly monotone, we have that

$$
\begin{aligned}
\left\|y_{n}-z\right\|^{2} & =\left\|J_{\lambda_{n}}\left(I-\lambda_{n} A\right) x_{n}-J_{\lambda_{n}}\left(I-\lambda_{n} A\right) z\right\|^{2} \\
& \leq\left\|x_{n}-\lambda_{n} A x_{n}-z+\lambda_{n} A z\right\|^{2} \\
& =\left\|x_{n}-z\right\|^{2}-2 \lambda_{n}\left\langle x_{n}-z, A x_{n}-A z\right\rangle+\lambda^{2}{ }_{n}\left\|A x_{n}-A z\right\|^{2} \\
& \leq\left\|x_{n}-z\right\|^{2}-2 \lambda_{n} \alpha\left\|A x_{n}-A z\right\|^{2}+\lambda_{n}^{2}\left\|A x_{n}-A z\right\|^{2} \\
& =\left\|x_{n}-z\right\|^{2}+\lambda_{n}\left(\lambda_{n}-2 \alpha\right)\left\|A x_{n}-A z\right\|^{2}
\end{aligned}
$$

From $(*)$, we have that

$$
\left\|y_{n}-z\right\|^{2} \leq\left\|x_{n}-z\right\|^{2}, \quad \forall n \in \mathbb{N}
$$


and hence

$$
\begin{aligned}
\left\|x_{n+1}-z\right\| & =\left\|\beta_{n} x_{n}+\left(1-\beta_{n}\right) T y_{n}-z\right\| \\
& \leq \beta_{n}\left\|x_{n}-z\right\|+\left(1-\beta_{n}\right)\left\|T y_{n}-z\right\| \\
& \leq \beta_{n}\left\|x_{n}-z\right\|+\left(1-\beta_{n}\right)\left\|y_{n}-z\right\| \\
& \leq\left\|x_{n}-z\right\| .
\end{aligned}
$$

This means that the condition (i) of Lemma 2.3 holds for $S=E$. We also obtain that $\lim _{n \rightarrow \infty}\left\|x_{n}-z\right\|$ exists. Thus, $\left\{x_{n}\right\},\left\{A x_{n}\right\},\left\{y_{n}\right\}$ and $\left\{T y_{n}\right\}$ are bounded. By the inequality (2),

$$
\begin{aligned}
\left\|x_{n+1}-z\right\|^{2} & \leq \beta_{n}\left\|x_{n}-z\right\|^{2}+\left(1-\beta_{n}\right)\left\|y_{n}-z\right\|^{2} \\
& \leq \beta_{n}\left\|x_{n}-z\right\|^{2}+\left(1-\beta_{n}\right)\left\{\left\|x_{n}-z\right\|^{2}+\lambda_{n}\left(\lambda_{n}-2 \alpha\right)\left\|A x_{n}-A x\right\|^{2}\right\} \\
& \leq\left\|x_{n}-z\right\|^{2}+\lambda_{n}\left(\lambda_{n}-2 \alpha\right)\left(1-\beta_{n}\right)\left\|A x_{n}-A z\right\|^{2} .
\end{aligned}
$$

Thus we have

$$
\begin{aligned}
0 & \leq(1-d) a(2 \alpha-d)\left\|A x_{n}-A z\right\|^{2} \\
& \leq\left\|x_{n}-z\right\|^{2}-\left\|x_{n+1}-z\right\|^{2} \rightarrow 0,
\end{aligned}
$$

as $n \rightarrow \infty$. This means that

$$
\lim _{n \rightarrow \infty}\left\|A x_{n}-A z\right\|=0 .
$$

On the other hand, since $J_{\lambda_{n}}$ is firmly nonexpansive, we have that

$$
\begin{aligned}
\left\|y_{n}-z\right\|^{2}= & \left\|J_{\lambda_{n}}\left(I-\lambda_{n} A\right) x_{n}-J_{\lambda_{n}}\left(I-\lambda_{n} A\right) z\right\|^{2} \\
\leq & \left\langle y_{n}-z,\left(I-\lambda_{n} A\right) x_{n}-\left(I-\lambda_{n} A\right) z\right\rangle \\
= & \frac{1}{2}\left\{\left\|y_{n}-z\right\|^{2}+\left\|\left(I-\lambda_{n} A\right) x_{n}-\left(I-\lambda_{n} A\right) z\right\|^{2}\right. \\
& \left.-\left\|y_{n}-z-\left(I-\lambda_{n} A\right) x_{n}+\left(I-\lambda_{n} A\right) z\right\|^{2}\right\} \\
= & \frac{1}{2}\left\{\left\|y_{n}-z\right\|^{2}+\left\|x_{n}-z\right\|^{2}\right. \\
& \left.-\left\|y_{n}-z-\left(I-\lambda_{n} A\right) x_{n}+\left(I-\lambda_{n} A\right) z\right\|^{2}\right\} \\
= & \frac{1}{2}\left\{\left\|y_{n}-z\right\|^{2}+\left\|x_{n}-z\right\|^{2}-\left\|y_{n}-x_{n}\right\|^{2}\right. \\
& \left.-2 \lambda_{n}\left\langle y_{n}-x_{n}, A x_{n}-A z\right\rangle-\lambda_{n}{ }^{2}\left\|A x_{n}-A z\right\|^{2}\right\} .
\end{aligned}
$$

Therefore we have

$$
\begin{aligned}
\left\|y_{n}-z\right\|^{2} \leq & \left\|x_{n}-z\right\|^{2}-\left\|y_{n}-x_{n}\right\|^{2} \\
& -2 \lambda_{n}\left\langle y_{n}-x_{n}, A x_{n}-A z\right\rangle-\lambda_{n}{ }^{2}\left\|A x_{n}-A z\right\|^{2}
\end{aligned}
$$


and hence

$$
\begin{aligned}
\left\|x_{n+1}-z\right\|^{2} \leq & \beta_{n}\left\|x_{n}-z\right\|^{2}+\left(1-\beta_{n}\right)\left\|T y_{n}-z\right\|^{2} \\
\leq & \beta_{n}\left\|x_{n}-z\right\|^{2}+\left(1-\beta_{n}\right)\left\|y_{n}-z\right\|^{2} \\
\leq & \beta_{n}\left\|x_{n}-z\right\|^{2}+\left(1-\beta_{n}\right)\left\{\left\|x_{n}-z\right\|^{2}-\left\|y_{n}-x_{n}\right\|^{2}\right. \\
& \left.-2 \lambda_{n}\left\langle y_{n}-x_{n}, A x_{n}-A z\right\rangle-\lambda_{n}{ }^{2}\left\|A x_{n}-A z\right\|^{2}\right\} \\
\leq & \left\|x_{n}-z\right\|^{2}-(1-d)\left\|y_{n}-x_{n}\right\|^{2}-\lambda_{n}{ }^{2}\left(1-\beta_{n}\right)\left\|A x_{n}-A z\right\|^{2} \\
& -2 \lambda_{n}\left(1-\beta_{n}\right)\left\langle y_{n}-x_{n}, A x_{n}-A z\right\rangle .
\end{aligned}
$$

This means that

$$
\begin{aligned}
& (1-d)\left\|y_{n}-x_{n}\right\|^{2} \leq\left\|x_{n}-z\right\|^{2}-\left\|x_{n+1}-z\right\|^{2} \\
& \quad+\left\|A x_{n}-A z\right\|\left\{2 b(1-c)\left\|y_{n}-x_{n}\right\|+b^{2}(1-c)\left\|A x_{n}-A z\right\|\right\} .
\end{aligned}
$$

Since $\left\{y_{n}\right\}$ and $\left\{x_{n}\right\}$ are bounded, $\lim _{n \rightarrow \infty}\left\|A x_{n}-A z\right\|=0$ and $\lim _{n \rightarrow \infty}\left\|x_{n}-z\right\|$ exists, we have

$$
\lim _{n \rightarrow \infty}\left\|y_{n}-x_{n}\right\|=0 .
$$

Since $A$ is Lipschitz continuous, we also have

$$
\lim _{n \rightarrow \infty}\left\|A y_{n}-A x_{n}\right\|=0 .
$$

Let $x^{*}$ be a weak cluster point of $\left\{x_{n}\right\}$. First, we prove that $x^{*} \in(A+B)^{-1}(0)$. Since $y_{n}=$ $J_{\lambda_{n}}\left(I-\lambda_{n} A\right) x_{n}$, we have that

$$
\begin{aligned}
& y_{n}=\left(I+\lambda_{n} B\right)^{-1}\left(I-\lambda_{n} A\right) x_{n} \\
& \Leftrightarrow\left(I-\lambda_{n} A\right) x_{n} \in\left(I+\lambda_{n} B\right) y_{n}=y_{n}+\lambda_{n} B y_{n} \\
& \Leftrightarrow x_{n}-y_{n}-\lambda_{n} A x_{n} \in \lambda_{n} B y_{n} \\
& \Leftrightarrow \frac{1}{\lambda_{n}}\left(x_{n}-y_{n}-\lambda_{n} A x_{n}\right) \in B y_{n} .
\end{aligned}
$$

Since $B$ is monotone, we have that for $(u, v) \in B$,

$$
\left\langle y_{n}-u, \frac{1}{\lambda_{n}}\left(x_{n}-y_{n}-\lambda_{n} A x_{n}\right)-v\right\rangle \geq 0
$$

and hence

$$
\left\langle y_{n}-u, x_{n}-y_{n}-\lambda_{n}\left(A x_{n}+v\right)\right\rangle \geq 0 .
$$

Suppose that a subsequence $\left\{x_{n_{j}}\right\} \subset\left\{x_{n}\right\}$ satisfies $x_{n_{j}} \rightarrow x^{*}$. Then, since $A$ is $\alpha$-inverse strongly monotone and $A x_{n} \rightarrow A z$ by (3),

$$
\left\langle x_{n_{j}}-x^{*}, A x_{n_{j}}-A x^{*}\right\rangle \geq \alpha\left\|A x_{n_{j}}-A x^{*}\right\|^{2}
$$


implies that $A x_{n_{j}} \rightarrow A x^{*}$ as $j \rightarrow \infty$. Moreover, since $\lim _{n \rightarrow \infty}\left\|y_{n}-x_{n}\right\|=0$ implies $y_{n_{j}} \rightarrow x^{*}$, we have

$$
\lim _{j \rightarrow \infty}\left\langle y_{n_{j}}-u, x_{n_{j}}-y_{n_{j}}-\lambda_{n_{j}}\left(A x_{n_{j}}+v\right)\right\rangle \geq 0
$$

and hence $\left\langle x^{*}-u,-A x^{*}-v\right\rangle \geq 0$. Since $B$ is maximal monotone, $\left(-A x^{*}\right) \in B x^{*}$. That is, $x^{*} \in(A+B)^{-1}(0)$.

Next, we show $x^{*} \in F(T)$. Putting $c=\lim _{n \rightarrow \infty}\left\|x_{n}-z\right\|$, we have

$$
\begin{aligned}
\limsup _{n \rightarrow \infty}\left\|T y_{n}-z\right\| & =\limsup _{n \rightarrow \infty}\left\|T y_{n}-T z\right\| \\
& \leq \limsup _{n \rightarrow \infty}\left\|y_{n}-z\right\| \\
& \leq \limsup _{n \rightarrow \infty}\left\|x_{n}-z\right\| \leq c .
\end{aligned}
$$

On the other hand, we have

$$
\lim _{n \rightarrow \infty}\left\|x_{n+1}-z\right\|=\lim _{n \rightarrow \infty}\left\|\beta_{n} x_{n}+\left(1-\beta_{n}\right) T y_{n}-z\right\|=c .
$$

From Lemma 2.1, we have

$$
\lim _{n \rightarrow \infty}\left\|\left(x_{n}-z\right)-\left(T y_{n}-z\right)\right\|=\lim _{n \rightarrow \infty}\left\|x_{n}-T y_{n}\right\|=0 .
$$

We have also

$$
\left\|y_{n}-T y_{n}\right\| \leq\left\|y_{n}-x_{n}\right\|+\left\|x_{n}-T y_{n}\right\| .
$$

Hence, we have

$$
\lim _{n \rightarrow \infty}\left\|y_{n}-T y_{n}\right\|=0 .
$$

Since $x_{n_{j}} \rightarrow x^{*}$ and $x_{n}-y_{n} \rightarrow 0$, we have $y_{n_{j}} \rightarrow x^{*}$. Now we shall show that $T x^{*}=x^{*}$. Since $T$ is nonspreading, we have

$$
\begin{aligned}
0 \leq & \left(\left\|T y_{n}-x^{*}\right\|^{2}-\left\|T y_{n}-T x^{*}\right\|^{2}\right)+\left(\left\|T x^{*}-y_{n}\right\|^{2}-\left\|T y_{n}-T x^{*}\right\|^{2}\right) \\
= & 2\left\langle T y_{n}, T x^{*}-x^{*}\right\rangle+\left\|x^{*}\right\|^{2}-\left\|T x^{*}\right\|^{2}+2\left\langle T y_{n}-y_{n}, T x^{*}\right\rangle+\left\|y_{n}\right\|^{2}-\left\|T y_{n}\right\|^{2} \\
\leq & 2\left\langle T y_{n}-y_{n}, T x^{*}-x^{*}\right\rangle+2\left\langle y_{n}, T x^{*}-x^{*}\right\rangle+\left\|x^{*}\right\|^{2}-\left\|T x^{*}\right\|^{2} \\
& +2\left\langle T y_{n}-y_{n}, T x^{*}\right\rangle+\left(\left\|y_{n}\right\|+\left\|T y_{n}\right\|\right)\left(\left\|y_{n}-T y_{n}\right\|\right) .
\end{aligned}
$$

Thus, we have that for all $j \in \mathbb{N}$,

$$
\begin{gathered}
0 \leq 2\left\langle T y_{n_{j}}-y_{n_{j}}, T x^{*}-x^{*}\right\rangle+2\left\langle y_{n_{j}}, T x^{*}-x^{*}\right\rangle+\left\|x^{*}\right\|^{2}-\left\|T x^{*}\right\|^{2} \\
+2\left\langle T y_{n_{j}}-y_{n_{j}}, T x^{*}\right\rangle+\left(\left\|y_{n_{j}}\right\|+\left\|T y_{n_{j}}\right\|\right)\left(\left\|y_{n_{j}}-T y_{n_{j}}\right\|\right) .
\end{gathered}
$$


Since $\lim _{n \rightarrow \infty}\left\|T y_{n_{j}}-y_{n_{j}}\right\|=0$ and $y_{n_{j}} \rightarrow x^{*}$ as $j \rightarrow \infty$, the above inequality implies that

$$
\begin{aligned}
0 & \leq 2\left\langle x^{*}, T x^{*}-x^{*}\right\rangle+\left\|x^{*}\right\|^{2}-\left\|T x^{*}\right\|^{2} \\
& =2\left\langle x^{*}, T x^{*}\right\rangle-\left\|x^{*}\right\|^{2}-\left\|T x^{*}\right\|^{2} \\
& =-\left\|x^{*}-T x^{*}\right\|^{2} .
\end{aligned}
$$

So, we have $T x^{*}=x^{*}$, i.e., $x^{*} \in F(T)$. Therefore we obtain that

$$
x^{*} \in E=F(T) \cap(A+B)^{-1}(0) .
$$

This implies that the condition (ii) of Lemma 2.3 holds for $S=E$. We also know that $\lim _{n \rightarrow \infty}\left\|x_{n}-z\right\|$ exists for $z \in S=E$. So, we have from Lemma 2.3 that there exists $z^{*} \in E$ such that $x_{n} \rightarrow z^{*}$ as $n \rightarrow \infty$. Moreover, since for any $z \in S=E$,

$$
\left\|x_{n+1}-z\right\| \leq\left\|x_{n}-z\right\|, \quad \forall n \in \mathbb{N},
$$

by Lemma 2.2 there exists some $z_{0} \in S$ such that $P_{S}\left(x_{n}\right) \rightarrow z_{0}$. The property of metric projection implies that

$$
\left\langle z^{*}-P_{S}\left(x_{n}\right), x_{n}-P_{S}\left(x_{n}\right)\right\rangle \leq 0 .
$$

Therefore, we have

$$
\left\langle z^{*}-z_{0}, z^{*}-z_{0}\right\rangle=\left\|z^{*}-z_{0}\right\|^{2} \leq 0 .
$$

This means that $z^{*}=z_{0}$, i.e., $x_{n} \rightarrow z^{*}=\lim _{n \rightarrow \infty} P_{E}\left(x_{n}\right)$.

\section{Applications}

Let $H$ be a Hilbert space and let $f$ be a proper lower semicontinuous convex function of $H$ into $(-\infty, \infty]$. Then the subdifferential $\partial f$ of $f$ is defined as follows:

$$
\partial f(x)=\{z \in H: f(x)+\langle z, y-x\rangle \leq f(y), \forall y \in H\}
$$

for all $x \in H$. By Rockafellar [11], it is shown that $\partial f$ is maximal monotone. Let $C$ be a nonempty closed convex subset of $H$ and let $i_{C}$ be the indicator function of $C$, i.e.,

$$
i_{C}(x) \begin{cases}0, & \text { if } x \in C, \\ \infty, & \text { if } x \notin C .\end{cases}
$$

Further, for any $u \in C$, we also define the normal cone $N_{C}(u)$ of $C$ at $u$ as follows;

$$
N_{C}(u)=\{z \in H:\langle z, y-u\rangle \leq 0, \forall y \in C\} .
$$

Then $i_{C}: H \rightarrow(-\infty, \infty]$ is a proper lower semicontinuous convex function on $H$ and $\partial i_{C}$ is a maximal monotone operator. Let $J_{\lambda} x=\left(I+\lambda \partial i_{C}\right)^{-1} x$ for $\lambda>0$ and $x \in H$. Since

$$
\begin{aligned}
\partial i_{C}(x) & =\left\{z \in H: i_{C}(x)+\langle z, y-x\rangle \leq i_{C}(y), \forall y \in H\right\} \\
& =\{z \in H:\langle z, y-x\rangle \leq 0, \forall y \in C\} \\
& =N_{C}(x)
\end{aligned}
$$


for $x \in C$, we have

$$
\begin{aligned}
u=J_{\lambda} x & \Leftrightarrow\left(I+\lambda \partial i_{C}\right)^{-1} x=u \\
& \Leftrightarrow x \in u+\lambda \partial i_{C}(u) \\
& \Leftrightarrow x \in u+\lambda N_{C}(u) \\
& \Leftrightarrow x-u \in \lambda N_{C}(u) \\
& \Leftrightarrow\langle x-u, y-u\rangle \leq 0, \quad \forall y \in C \\
& \Leftrightarrow P_{C}(x)=u .
\end{aligned}
$$

Similarly, we have that for $x \in C$,

$$
\begin{aligned}
x \in\left(A+\partial i_{C}\right)^{-1}(0) & \Leftrightarrow\langle-A x, y-x\rangle \leq 0, \quad \forall y \in C \\
& \Leftrightarrow x \in V I(A, C) .
\end{aligned}
$$

Thus, putting $B=\partial i_{C}$, we have $J_{\lambda_{n}}=P_{C}$ for any $n \in \mathbb{N}$. Thus, we have the following theorem from Theorem 3.1.

Theorem 4.1. Let $C$ be a nonempty closed convex subset of a real Hilbert space $H$, let $A$ be an $\alpha$-inverse strongly monotone mapping of $C$ into $H$ and let $T: C \rightarrow C$ be a nonspreading mapping. Assume $F(T) \cap\left(A+\partial i_{C}\right)^{-1}(0)=F(T) \cap V I(A, C) \neq \emptyset$. Define a sequence $\left\{x_{n}\right\}$ in $C$ as follows: $x=x_{1} \in C$ and

$$
x_{n+1}=\beta_{n} x_{n}+\left(1-\beta_{n}\right) T\left(P_{C}\left(I-\lambda_{n} A\right) x_{n}\right)
$$

for all $n \in \mathbb{N}$, where the sequences $\left\{\beta_{n}\right\}$ and $\left\{\lambda_{n}\right\}$ satisfy the condition $(*)$ :

$$
0<c \leq \beta_{n} \leq d<1 \text { and } 0<a \leq \lambda_{n} \leq b<2 \alpha .
$$

Then, $x_{n} \rightarrow z_{0} \in F(T) \cap V I(A, C)$ and $z_{0}=\lim _{n \rightarrow \infty} P_{F(T) \cap V I(A, C)}\left(x_{n}\right)$.

Let $S: C \rightarrow C$ be nonexpansive. Then, $I-S$ is $\frac{1}{2}$-inverse strongly monotone. So, we obtain the following result.

Theorem 4.2. Let $C$ be a nonempty closed convex subset of a real Hilbert space $H$, let $S: C \rightarrow$ $C$ be a nonexpansive mapping and let $T: C \rightarrow C$ be a nonspreading mapping. Assume that $F(T) \cap F(S) \neq \emptyset$. Let $x=x_{1} \in C$ and define

$$
x_{n+1}=\beta_{n} x_{n}+\left(1-\beta_{n}\right) T\left(\left(1-\lambda_{n}\right) x_{n}+\lambda_{n} S x_{n}\right)
$$

for all $n \in N$, where $\left\{\lambda_{n}\right\}$ and $\left\{\beta_{n}\right\}$ satisfy the condition $(*)$ :

$$
0<c \leq \beta_{n} \leq d<1 \text { and } 0<a \leq \lambda_{n} \leq b<1 .
$$

Then, $x_{n} \rightarrow z_{0} \in F(T) \cap F(S)$ and $z_{0}=\lim _{n \rightarrow \infty} P_{F(T) \cap F(S)}\left(x_{n}\right)$. 
Proof. Put $A=I-S$. Then we have

$$
\begin{aligned}
P_{C}\left(x_{n}-\lambda_{n} A x_{n}\right) & =P_{C}\left(x_{n}-\lambda_{n}(I-S) x_{n}\right) \\
& =P_{C}\left(\left(1-\lambda_{n}\right) x_{n}+\lambda_{n} S x_{n}\right) \\
& =\left(1-\lambda_{n}\right) x_{n}+\lambda_{n} S x_{n} .
\end{aligned}
$$

For $u \in C$, we have $S u \in C$ and

$$
\begin{aligned}
u \in\left(A+\partial i_{C}\right)^{-1}(0) & \Leftrightarrow 0 \in A u+N_{C}(u) \\
& \Leftrightarrow S u-u \in N_{C}(u) \\
& \Leftrightarrow\langle S u-u, v-u\rangle \leq 0, \forall v \in C \\
& \Leftrightarrow P_{C}(S u)=u \\
& \Leftrightarrow S u=u .
\end{aligned}
$$

Thus, we obtain $\left(A+\partial i_{C}\right)^{-1}(0)=V I(A, C)=F(S)$. So, by Theorem 4.1 we have the desired result.

Next, we deal with the equilibrium problem with nonspreading mappings in a Hilbert space. Takahashi, Takahashi and Toyoda [15] showed the following.

Theorem 4.3 ([15]). Let $C$ be a nonempty closed convex subset of a Hibert space $H$ and let $f: C \times C \rightarrow \mathbb{R}$ be a bifunction satisfying the conditions (A1)-(A4). Define $A_{f}$ as follows:

$$
A_{f}(x) \begin{cases}\{z \in H: f(x, y) \geq\langle y-x, z\rangle, \forall y \in C\}, & \text { if } x \in C, \\ \emptyset, & \text { if } x \notin C .\end{cases}
$$

Then, $\operatorname{EP}(f)=A_{f}^{-1}(0)$ and $A_{f}$ is maximal monotone with the domain of $A_{f}$ in $C$. Furthermore,

$$
T_{r}(x)=\left(I+r A_{f}\right)^{-1}(x), \quad \forall r>0 .
$$

We obtain the following theorem from Theorem 3.1.

Theorem 4.4. Let $C$ be a nonempty closed convex subset of a real Hilbert space $H$, let $f: C \times C \rightarrow$ $\mathbb{R}$ satisfy the conditions (A1)-(A4) and let $T_{\lambda}$ be the resolvent of $f$ for $\lambda>0$. Let $S: C \rightarrow C$ be a nonspreading mapping. Assume that $F(T) \cap E P(f) \neq \emptyset$. For $x=x_{1} \in C$, define

$$
x_{n+1}=\beta_{n} x_{n}+\left(1-\beta_{n}\right) S T_{\lambda_{n}} x_{n}, \quad \forall n \in \mathbb{N}
$$

where $\left\{\beta_{n}\right\}$ and $\left\{\lambda_{n}\right\}$ satisfy the following conditions:

$$
0<c \leq \beta_{n} \leq d<1, \quad 0<a \leq \lambda_{n} \leq b<\infty
$$

Then, $x_{n} \rightarrow z_{0} \in F(T) \cap E P(f)$ and $z_{0}=\lim _{n \rightarrow \infty} P_{F(S) \cap E P(f)}\left(x_{n}\right)$. 
Proof. Suppose $A=0$. Then, we have that

$$
\langle x-y, A x-A y\rangle \geq \alpha\|A x-A y\|^{2}=0, \quad \forall \alpha \in \mathbb{R} .
$$

So, we can choose $\alpha=\infty$ in Theorem 3.1. Since $T_{\lambda_{n}}=\left(I+\lambda_{n} A_{f}\right)^{-1}$ is the resolvent of $A_{f}$ and $A_{f}$ is maximal monotone, Theorem 3.1 implies that $x_{n} \rightarrow z_{0} \in F(T) \cap A_{f}^{-1}(0)$. Moreover, we know $A_{f}^{-1}(0)=E P(f)$. So, we have the desired result.

Received: June 2009. Revised: September 2009.

\section{References}

[1] E. Blum And W. Oettli, From optimization and variational inequalities to equilibrium problems, Math. Student 63 (1994), 123-145.

[2] P. L. Combettes and A. Hirstonga, Equilibrium programming in Hilbert spaces, J. Nonlinear Convex Anal. 6 (2005), 117-136.

[3] S. Iemoto And W. Takahashi, Approximating common fixed points of nonexpansive mappings and nonspreading mappings in a Hilbert space, to appear.

[4] T. Igarashi, W. TAKahashi And K. TANAKA, Weak convergence theorems for nonspreading mappings and equilibrium problems, to appear.

[5] H. IIDUKA AND W. TAKAHASHI, Weak convergence theorem by Cesàro means for nonexpansive mappings and inverse-strongly monotone mappings, J. Nonlinear Convex Anal. 7 (2006), $105-113$

[6] F. Kosaka and W. TAKahashi, Existence and approximation of fixed points of firmly nonexpansive-type mappings in Banach spaces, SIAM. J.Optim. 19 (2008), 824-835.

[7] F. Kosaka and W. Takahashi, Fixed point theorems for a class of nonlinear mappings related to maximal monotone operators in Banach spaces., Arch. Math. (Basel) 91 (2008), 166-177.

[8] A. Moudafi, Weak convergence theorems for nonexpansive mappings and equilibrium problems, J. Nonlinear Convex Anal., to appear.

[9] A. Moudafi And M. ThÉRA, Proximal and dynamical approaches to equilibrium problems, Lecture Notes in Economics and Mathematical Systems, 477, Springer, 1999, pp.187-201.

[10] Z. OpIAL, Weak covergence of the sequence of successive approximations for nonexpansive mappings, Bull. Amer. Math. Soc. 73 (1967), 591-597. 
[11] R. T. Rockafellar, On the maximal monotonicity of subdifferential mappings, Pacific J. Math. 33 (1970), 209-216.

[12] J. Schu, Weak and strong convergence to fixed points of asymptotically nonexpansive mappings, Bull. Austral. Math. Soc. 43 (1991), 153-159.

[13] A. TAda And W. TAkAhashi, Strong convergence theorem for an equilibrium problem and a nonexpansive mapping, J. Optim. Theory Appl., in press.

[14] S. TAKahashi and W. TAKahashi, Viscosity approximation methods for equilibrium problems and fixed point problems in Hilbert spaces, J. Math. Anal. Appl. 331 (2007), 506-515.

[15] S. Takahashi, W. Takahashi and M. Toyoda, Strong convergence theorems for maximal monotone operators with nonlinear mappings in Hilbert spaces, to appear.

[16] W. Takahashi, Nonlinear Functional Analysis, Yokohama Publishers, Yokohama, 2000.

[17] W. Takahashi, Convex Analysis and Approximation of Fixed Points (Japanese), Yokohama Publishers, Yokohama, 2000.

[18] W. Takahashi, Introduction to Nonlinear and Convex Analysis (Japanese), Yokohama Publishers, Yokohama, 2005.

[19] W. TAKahashi And M. ToyodA, Weak convergence theorems for nonexpansive mappings and monotone mappings, J. Optim. Theory Appl. 118 (2003), 417-428.

[20] K. K. TAN And H. K. Xu, Approximating fixed points of nonexpansive mappings by the Ishikawa iteration process, J. Math. Anal. Appl. 178 (1993), 301-308.

[21] H. K. XU, Another control condition in an iterative method for nonexpansive mappings, Bull. Austral. Math. Soc. 65 (2002), 109-113.

[22] H. K. XU, Viscosity approximation methods for nonexpansive mappings, J. Math. Anal. Appl. 298 (2004), 279-291. 